\title{
A REVIEW AND UPDATE OF EXPERIMENT AND CLINICAL STUDIES OF SPINAL CORD INJURY ${ }^{1,2}$
}

\author{
By W. F. Collins, M.D. \\ Cushing Professor of Surgery, Chief, Section of Neurological Surgery, Yale University \\ School of Medicine, New Haven, Connecticut, U.S.A.
}

I would like to express my appreciation for the invitation to give this lecture honouring Professor Norman Dott. I first met Professor Dott when I was a resident and later had a chance to get to know him better when I was a young neurosurgical faculty member. He was one of the giants of neurosurgery, and he was one giant that on meeting did not disappoint a neophyte. He was gentlemanly, academically caustic in a conference or discussion, was confident, but not overbearing, and judged people by his own and sometimes unusual standards. He almost overwhelmed me by spending time listening to some work I was doing to support a hypothesis about pain. I might add, his comments were pertinent and helpful even though the subject was not of prime interest to him. Norman Dott did what every young neurosurgeon hopes he or she can do. He became a master surgeon, contributed to the development of his chosen field and trained pupils to continue his influence. Perhaps one of the reasons for his success was his ability to get succintly to the heart of the matter. Sometimes when I do a transsphenoidal approach to the pituitary, I remember his brief but caustic comment when I told him early in my career that I was not using the approach, because I had been taught it resulted in inadequate resections. He implied I hadn't thought the situation through. I quote him, certainly not word for word but in the sense of his meaning, 'No matter what you were taught, you should know the major reason remains that the patients do better'. Perhaps we, working in the area of spinal cord injury, are missing something that will allow 'the patients to do better'. I an certain, he would like us to find that something.

The title of my talk is A Review and Update of Experimental and Clinical Studies of Spinal Cord Injury. You will have to allow me in condensing such a broad subject to emphasise my interests and not be upset if this prejudice omits some aspects that you feel are important.

I am certain that all of you are aware that a professor of neurosurgery cannot and does not physically nor even conceptually do all the work he presents from his department. Since I will try to present a considerable amount of work in a brief time and cannot give individual credit to my co-workers for what they contributed, I would like to thank them for making this lecture possible and for making my professional life more interesting and satisfying. The National Institute of Neurological Communicative Diseases and Stroke (NINCDS) of the National Institutes of Health in the

\footnotetext{
${ }^{1}$ Norman Dott Memorial Lecture, International Conference on Recent Advances in Neurotraumatology, 2 I September I982, University of Edinburgh, Edinburgh, Scotland.

2 Supported in part by NINCDS programme grant \# NS IOI 74
} 
United States has for the past decade supported centres for the study of the acute care of spinal cord injury, and Yale has received one of these centre grants. I wish to thank the Institute, for without their support our experimental group could not have functioned nor even existed in its present form.

It was not until late in the last century that progress was made in the study of spinal cord injury. The early impact models of Schamus ( 1890 ), Watson (I89I) and Spiller (I899), (Dohrmann, I972), produced varied histological changes but suggested the possibility that a progressive lesion occurred following the injury. To study this lesion, a reproducible standardised spinal cord lesion was required and, Allen in I9I I and I9I4, developed the drop weight model capable of producing graded lesions quantified as $\mathrm{gm} / \mathrm{cm}$ of impact measured by the product of the weight times the distance it was dropped. With this model, descriptions of partial and complete lesions, the low threshold of the grey matter to contusion, the resulting central haemorrhagic changes and the cavitation that occurs following an impact injury have evolved (McVeigh, I923; Ferraro, 1927; Ducker et al., I97I). Modifications of the Allen model have been the most commonly used experimental model for the study of spinal cord injury. There have been other models. Cajal (Ramon Y Cajal, I982) in the second decade of this century studied the changes that occurred at the site of a sharp transverse lesion of the mammallian spinal cord and described the formation of axonal terminal end-bulbs that appear similar but larger than the growth cones of peripheral nerves. He also described the autolysis of 200 to 700 microns of the edge of the spinal cord at both borders of the lesion. Another model that has had considerable study is the compressive injury model as used by Tarlov and his co-workers and Tator and his co-workers. Tarlov (I953, I954a, I954b, I957) used an epidural balloon for rapid and slow compression and Tator and his co-workers (Tator, I972; Deecke and Tator, I973; Tator, I973; Rivlin and Tator, 1977; Rivlin and Tator, 1978) first used a compressing circumferential sleeve and more recently a spring clip. While the compressive models improve the reproducibility of the lesion, a question as to the model's relationship to the clinical situation of an acute impact remains. In all models the same process described by Cajal occurs but over a larger area, contributes to the cavitation that follows cord injury and the process has been proposed as one of the barriers to spinal cord regeneration. The process has been shown to proceed in transverse, caudal and rostral directions, and has been used in support of the concept of a progressive secondary injury.

A major impetus for the experimental study of spinal cord injury has been this concept of secondary injury or the hypothesis that response of the spinal cord to injury causes a portion of the resulting neurological dysfunction. Using a variation of the Allen drop weight model, one of the first to test experimentally that hypothesis, was Freeman and his coworkers in the late I 940 S and early I 950 s who proposed that loss of vascular perfusion secondary to pial encasement of an oedematous haemorrhagic contused spinal cord was the cause of secondary injury (Freeman and Wright, I953; Joynes and Freeman, 1963). They reported an improvement in expected neurological dysfunction when myelotomy or hypertonic solution was used as a treatment for graded impact injury. In the I960s Albin and White and their co-workers (Albin et al., I968) reported a protected effect 
of local hypothermia on primate and canine spinal cord when applied within a few hours of impact injury, proposing that hypometabolism protected the injured spinal cord from secondary injury. This suggested a metabolic cause of the secondary injury. No evidence from the clinical use of myelotomy, solute diuretics or local hypothermia has supported these experimental findings although it must be said that none of the clinical studies to test these therapies was designed to overcome the problems that are inherent in clinical studies of spinal cord injury. Osterholm in the I970s.(Osterholm and Mathews, I972a) proposed that accumulation of norepinephrine at the site of injury caused localized vasoconstriction and membrane disruption. He supported this hypothesis by showing the protective effect of alpha methyltyrosine an inhibitor of the synthesis of norepinephrine in decreasing the central haemorrhagic changes (Osterholm and Mathews, I972b). These studies were an impetus to the NINCDS to support more work on experimental spinal cord injury and, therefore, were valuable, but their results failed to stand up to further investigation. We were interested in Osterholm's hypothesis since there are drugs, safer than alpha methyltyrosine, that can inhibit synthesis of biogenic amines. The concentration of norepinephrine in normal cat spinal cord varies from level to level (Rawe et al., I972a) but no increase of norepinephrine was found at the site of an experimentally produced contusive injury (Naftchi et al., 1974; Rawe et al., I977b; Rawe et al., I977c). Alpha methyltyrosine causes hypotension and we could duplicate the decrease in central haemorrhage that he found, with hypotension, which, however, caused increase in the resultant neurological deficit.

Let me take a few minutes to discuss the impact model of spinal cord injury. There are many problems in using it and they should be considered when evaluating experimental studies (Collins and Kauer, 1979). Physiological factors that alter blood flow or metabolism, alter outcome, and the minimal controls in any experimental spinal cord injury model must include, body temperature, blood pressure, $\mathrm{PO}_{2}, \mathrm{PCo}_{2}$ and blood $\mathrm{pH}$ (de la Torre and Boggan, I980). Many studies have failed to consider these controls and entered variables that make interpretations of the result difficult or impossible. A major technique in studying possible causes of secondary injury is to determine the effect of various treatment regimes on expected neurological dysfunction following an injury (Ducker and Hamit, I969; Campbell et al., I973; de la Torre, I98I). It is thus important that experimental spinal cord injury outcome be predictably consistent. Several studies have assumed that in the Allen model a particular $\mathrm{gm} / \mathrm{cm}$ force as measured by weight size and distance dropped defines a lesion and its expected neurological deficit. Our laboratory has shown a correlation of resultant neurological deficit and size of spinal cord lesion measured both in volume and maximum cross sectional diameter. Dohrmann, Panjabi and Banks (1978) measuring volume size of the lesion showed no correlation between volume of the lesion and $\mathrm{gm} / \mathrm{cm}$ measurements of the drop weight model or impounder velocity but rather a correlation with energy and impact transmitted. They demonstrated a five fold difference in lesions produced by a $400 \mathrm{gm} / \mathrm{cm}$ impact in the cat when height and weight were changed to keep this product constant. Other variables in the Allen model such as the type of animal, size of the weight, shape of the impact surface, not using or using an impounder resting on the dura and its shape and type of spinal 
column fixation all alter the type and extent of the lesion produced (Tator, I972). It is important that any technique used is carefully evaluated in the laboratory using it, and continually checked as a control during any experimental study, to be certain an unobserved variable has not appeared, or a variable altered, altering the expected outcome. Another concept when evaluating a study of secondary injury is that of the trauma-dose curve (Collins and Kauer, I979). It is apparent that at the lower end or low impact portion of the curve that almost all therapies as well as time will improve the neurological loss which is usually transient and, therefore, the ability to evaluate a therapy is difficult. At the high impact end of the curve only regeneration might be expected to work since physical interruption of fibers may have occurred. There is a sharp straight slope of the trauma-dose, neurological deficit curve in our laboratories in the cat showing both the narrow range where our model of impact injury can be used to study therapy and the single expotential quality of the curve suggesting that a single factor, impact itself, is the major determinant of the curve.

Our studies as well as studies from other laboratories have indicated that changes in spinal blood flow and the production of oedema may alone or in combination be a factor in secondary injury (Griffiths, 1976; Stewart and Wagner, I979). Post experimental spinal cord blood flow has been measured in our laboratories by the hydrogen clearance method and by carbon-I 4 antipyrine autoradiography (Senter and Venes, I978; Senter and Venes, 1979). The studies demonstrate loss of autoregulation 30 to 40 minutes after injury with decrease in local spinal blood flow, with post injury decrease in systemic blood pressure, and increase in local spinal cord blood flow with elevation in blood pressure. Both post injury hypotension and hypertension, the latter probably secondary to increased central haemorrhage, cause increased neurological deficit. More recent work has shown that reactivity of the local blood vessels to changes in $\mathrm{pH}$ and $\mathrm{PCo}_{2}$ remains at a time when autoregulation to pressure has been lost and these complex combinations may explain some of the discrepancies reported in many post experimental spinal cord injury blood flow studies. Although the amount of oedema and its distribution does roughly correlate with the amount of force applied to the cord, in the intermediate zone of the traumadose curve which appears to be the most important portion of the curve to study, the amount of oedema formation and its extent does not correlate with neurological loss. The distribution of oedema following an impact injury as seen in fluorescent histological studies with fluorosine tagged albumin as the agent being photographed, is along white matter tracts of the cord (Stewart and Wagner, I979). It can extend considerable distances cephalad and rostrad and is reminiscent of the white matter spread seen in cerebral hemisphere injuries. Studies attempting to alter the extent and distribution of oedema have not been as fruitful as had been expected. The agents used have included both hypertonic solutions and steroids. Our emphasis in the laboratory has shifted to the study of early changes in the axons, that is, within hours of injury and its relation to oedema and blood flow rather than just the study of oedema following impact injury.

Table I lists drugs and treatments that have been shown to have an effect on the expected outcome of neurological deficit produced by experimental spinal cord injury (Black and Markowitz, I97I; Campbell et al., I974; Hedeman et al., I974a; Hedeman et al., I974b; Lewin et al., I974; 


\section{TABLE I}

Treatments that alter expected neurological outcome in experimental models of spinal cord injury

\begin{tabular}{ll}
\hline Positive & Negative \\
\hline Carbonic anhydrase inhibitors & Alcohol \\
Corticosteroids & Hypertension \\
Dimethylsulfoxide & Hypotension \\
Hyperbaric oxygen & \\
Local hypothermia & \\
Local isotonic perfusion & \\
Myelotomy & \\
Naloxone & \\
Osmotic diuretics & \\
TSH-Thyroxine & \\
\hline
\end{tabular}

Flamm et al., I977; Nemecek, I978; de la Torre and Boggan, I980; Dolan et al., I980; Brodner et al., I98I; Faden et al., I98Ia; Faden et al., I98Ib; Hall and Braughler, $198 \mathrm{I}$; Means et al., 198I; Young et al., 198I; Braughler and Hall, 1982; Flamm et al., 1982; Hall and Braughler, I982). The changes in the expected neurological deficits in the above protocols have been confirmed by more than one laboratory but almost all agents have in some study failed to show an effect in one or more other laboratories, which is one of the reasons I mentioned the controls necessary and the trauma dose curve concept in impact models. Taking the entire group together the experimental results indicate that some process or combination of processes produce a secondary injury that may be amenable to therapy. Whether this is caused by altered blood supply, oedema, breakdown of organelles and the release of lysosomal enzymes, by disruption of the adjacent tissues from the pressure of the enlarging end-bulbs, by calcium influx into the cut end of the axons, by prostaglandin cascade effect on the surrounding tissue, by local biogenic amine concentration, or by some unknown factor or a combination of these remain unproven hypotheses. I will not go into the hypotheses of the mechanisms proposed on the basis of results obtained from experimental treatment protocols but rather summarise my interpretation as follows:

I. A secondary injury results from the reaction of the spinal cord to injury.

2. There is more than one mechanism causing the injury.

3. Aberations in spinal cord blood flow including alterations in microcirculation may be a factor. Agents causing vasoconstriction, vasodilitation, alteration in endothelial cell integrity, and/or changes in platelet aggregation may alone or in combination contribute to the secondary injury.

4. Biochemical and mechanical alteration of cell membranes are another factor. The possible biochemical agents are many.

5. While oedema formation may contribute to the mechanical dis- 
ruption of membranes, it appears to be an epiphenomena, well tolerated within wide ranges both of extent and amounts in white matter.

A major limiting factor with experiments concerning secondary injury have been that they consist mainly of recording phenomena related to the effect of different therapy and have not examined in an organised fashion the mechanisms involved. These basic mechanism areas must be studied and since the numbers of possible factors present at the site of injury precludes a treatment shotgun approach, the defining of basic mechanisms involved, and the time sequence of their activity, appears to be the direction to proceed.

While the difficulties involved in the evaluation of the experimental studies of spinal cord injury are a problem, these difficulties are exponentially increased in number and complexity in the evaluation of the clinical aspects of spinal cord injury. An aspect not involved in animal studies is that of the impact of spinal cord injury on society. Not counting the loss of productivity of the victims, the direct medical care costs of new spinal cord injuries in the United States, is over a half billion dollars a year and with the present life expectancy of spinal cord injured patients and medical care necessary for their survival, the resulting medical cost total is well past a billion and a half dollars a year. The majority of these costs in the United States are born by the Federal Government even in our private medical care society. To plan for the effective use of such sums of money, accurate epidemiological studies were required and the National Institutes of Health have supported epidemiological studies as well as experimental and clinical studies of spinal cord injury in order to determine what is needed and what might be done both for the victim and for society.

In the past few decades a number of epidemiological studies have been published that have shown marked variations in incidence, severity and costs of spinal cord injury. Table II is an example of the variations in the reported incidences of spinal cord injury from four countries, with three of the studies coming from the North American continent and two from the United States (Benes, I968; Gehrig and Michaelis, I 968; Sutton, I973; Botteral et al., I975; Kraus et al., 1975; Webb et al., 1978). Despite similar conditions in the North American areas studied, there is almost a four fold difference in incidence and almost a five fold difference among the different countries. Part of the problem is what constitutes a reported case and how

TABLE II

Epidemiological studies of spinal cord injury

\begin{tabular}{lllccl}
\hline Author & Year & Area & Pop/M & Rate/M & Comment \\
\hline Benes & I952-67 & Czechoslovakia & I3 & I2 & Hospital discharges \\
Botterell & I969-70 & Canada & $7 \cdot 6$ & I5 & Hospital admissions \\
Kraus & I970-71 & California & $5 \cdot 8$ & 53 & All cases \\
Webb & I975-76 & Connecticut & $3 \cdot 3$ & 28 & Hospital admissions \\
Gehrig & I968 & Switzerland & $5 \cdot 5$ & 13 & Hospital questionnaire \\
Sutton & I963-70 & Australia & I.8 & I4 & Spinal cord centres \\
\hline
\end{tabular}


is it identified. Kraus' study from California with the highest incidence of 55 per million included all injuries, those that died before admission to a hospital, those that were admitted, those that were seen but not admitted, and those identified by any means within a defined population. The same study showed an incidence of hospital admissions of about 33 per million, similar to the 28 per million shown by Webb et al. (Webb et al., 1978) of our group at Yale in 1975-76. That survey was of all spinal cord injury hospital admissions in Connecticut. Bracken et al. (Bracken et al., I98I) of our faculty, in trying to develop a less costly method used identified hospital discharge codes in the data bank of the National Center for Health Statistics and a subset to correct for multiple admissions, and arrived at a figure of approximately 40 per million spinal cord injury hospital admisşions per year. A I 980 study of the National Institute of Health using a selective population survey arrived at a figure of 50 per million population/year. I mention these variations in the studies not to criticise the studies but to point out the problems that have arisen in attempting to define as simple a portion of the clinical problem as the incidence of the event of spinal cord injury in our population. There is, with more sophisticated techniques, a concensus being attained in this quest of an incidence at about $45 / \mathrm{mil} /$ $\mathrm{pop} / \mathrm{yr}$ in the United States. No such concensus is being approached in other aspects of the problems of spinal surgery.

The British Isles are famous in our medical meetings, and our malpractice courts for non-interventional care of spinal cord injury with the results from the Stoke Mandeville group being the basis to indicate that the non-surgical postural reduction approach is more effective than the relatively common concept in the States of rapid reduction and frequently early surgical intervention (Frankel et al., 1967). I would like to review a few of these clinical studies. Table III is to briefly remind you of the Frankel Functional Classification of spinal cord injury that can be used for

\section{TABLE III}

Summary of Frankel's functional classification of spinal cord injury

A-No sensory or motor function
B-Incomplete sensory-No motor function
C-Incomplete sensory-No useful motor function
D-Incomplete sensory-Useful motor function
E-Normal function-May have spasticity

comparing different series. The A group is a total lesion and the $\mathrm{E}$ group is normal function with or without abnormal reflexes. In order to decrease variables, I have picked cervical spinal cord injuries. There are enough variables in any clinical series to please the most dedicated biostatistician and using one anatomical area helps limit if not overcome some of these variables. Table IV is a review of three modern series-one the Stoke Mandeville series and the other two from the States and one not so modern series (Hartwell, I917; Frankel et al., 1967; Young and Dexter 1978; Maynard et al., 1979). The vertical axis of each box is the functional grading on admission to and the horizontal axis on discharge from the hospital. Thus, 


\section{TABLE IV}

Four clinical series of spinal cord injury. Vertical axis is Frankel's classification on admission; horizontal axis on discharge

\begin{tabular}{|c|c|c|c|c|c|c|c|c|c|}
\hline \multicolumn{5}{|c|}{ Stoke Mandeville } & \multicolumn{5}{|c|}{ Southwest Region } \\
\hline A & B & $\mathrm{C}$ & $\mathrm{D}$ & $E$ & $\mathrm{~A}$ & B & $\mathrm{C}$ & $\mathrm{D}$ & $E$ \\
\hline A $8 I$ & $2 \mathrm{I}$ & IO & I I & 0 & A 4 I & 6 & I & I & 0 \\
\hline B 3 & 9 & 2 & I4 & 5 & B & 4 & 2 & IO & 0 \\
\hline C & I & 4 & I I & 5 & C & 0 & 2 & 3 & 0 \\
\hline D & 0 & 0 & 30 & I I & D & 0 & 0 & I 4 & 6 \\
\hline E $\quad$ o & 0 & 0 & 0 & 0 & $\mathrm{E}$ & 0 & 0 & 3 & 0 \\
\hline \multicolumn{5}{|c|}{$\mathrm{N}=2 \mathrm{I} 8$} & \multicolumn{5}{|c|}{$N=95$} \\
\hline \multicolumn{5}{|c|}{ California Region } & \multicolumn{5}{|c|}{ MGH Boston I9I7 } \\
\hline A & B & C & D & $E$ & A & B & C & $\mathrm{D}$ & E \\
\hline A 50 & & 3 & 4 & I & A 25 & 0 & 0 & 0 & 0 \\
\hline & 3 & 2 & 13 & 0 & B 2 & 0 & 0 & 2 & 0 \\
\hline C & 0 & 2 & 17 & 4 & C & 0 & 0 & I & I \\
\hline D & & 0 & 4 & 7 & $\mathrm{D} \quad 0$ & 0 & 0 & 0 & 0 \\
\hline E $\quad$ o & 0 & 0 & 0 & 0 & E o & 0 & 0 & 0 & 0 \\
\hline $\mathbf{N}=$ & & & & & $\begin{array}{l}\mathrm{N}=3 \\
\mathrm{~A}=\mathrm{M} \\
88 \text { per }\end{array}$ & & & & \\
\hline
\end{tabular}

as in the Southwest Region series a patient with a ' $C$ ' on admission and an ' $A$ ' on discharge deteriorated while one with a ' $B$ ' on admission and a ' $D$ ' on discharge improved. Unchanged patients form an oblique line from the upper left hand corner, that is, the 'AA', 'BB' to the lower right hand corner of each block. In case you are discouraged with the present treatment of spinal cord injury, the fourth box was made by extrapolation of data presented by James Hartwell in an article published in 1917 in the Boston Medical and Surgical Journal (Hartwell, I9I7). It consisted of a series of I33 cases of spinal cord injury admitted to the Massachusetts General Hospital between I900 and I9I4, 34 patients had cervical spinal cord injuries. The only change in that box is that the ' $\mathrm{A}$ ' discharge line is mortality because with one exception no one with a complete lesion on admission survived, and that exception died I I months after admission. The causes of spinal cord injury in the Boston series had a different distribution than modern series with 62 per cent caused by falls, 19 per cent from forces that cause acute flexion, such as, sports or falling objects, 5 per cent from altercations, with no mention of gunshot wounds and 8 per cent from vehicle accidents. The majority of the vehicles accidents involved trains but one was an automobile accident. Twenty-three of the cervical spinal cord injury patients were $\mathrm{X}$-rayed and twelve fractures were diagnosed. The use of $\mathrm{X}$-ray for diagnosis was just starting and a comment was made of the difficulty in diagnosing fractures of the cervical spinal column with an anterior/posterior X-ray and the difficulty in obtaining lateral X-rays of 
the lower cervical spine. Eleven of the 34 patients underwent laminectomies, 7 within the first 24 hours and 9 within the first week, evidence for some historical continuity of opinion in the States. There were ro postoperative deaths including one patient each in ' $\mathrm{B}$ ' and ' $\mathrm{C}$ ' category on admission to the Massachusetts General Hospital. The eleventh patient who improved after a laminectomy from an ' $A$ ' on admission to a ' $C$ ', developed complications and remained at the hospital until he died 8 months later from renal failure. While listed as a complete lesion on admission, at post-mortem examination he showed a significant portion of the spinal cord intact and Mixter and Chase reported this case in 1904 as evidence of the value of laminectomy in protecting the injured spinal cord (Mixter and Chase, I904). Dr Hartwell, however, concluded from this series that laminectomy was not of value and postulated that at least two patient might have had functional return if they had not been operated upon and that the remainder benefited only by having their agony shortened by the surgery.

This attitude of despair concerning spinal cord injured patients prevailed up to and through most of World War II, even though Riddoch and Head in England during World War I had shown that paraplegic patients could survive when given the correct care. With these surviving patients, Riddoch in I9I7, (Riddoch, I9I7) settled the long standing argument as to whether the isolated human spinal cord functioned and, therefore, laid the groundwork for possible treatment by techniques of regeneration. He demonstrated spinal reflexes in the human and their loss with sepsis and joint contraction. The spinal cord injury patients however who survived often became nonfunctional chronic nursing patients, addicted to opiates and usually succumbed within a year or two to urinary tract dysfunction, sepsis from decubiti and/or pulmonary disease. It was the concepts and the enthusiasm of Sir Ludwig Guttmann in England who almost single handedly changed this. He believed and demonstrated that with appropriate care the associated complications of spinal cord injury could be controlled indefinitely and that with rehabilitation the spinal cord injury victim could be returned to an independent productive life. This led to the Stoke Mandeville Centre concept and the results led to changes throughout the entire western world as to how spinal cord injury should be handled. His success was so great that his concepts of the treatment of spinal cord injury became almost revered and in much of the western world questioning and investigation of the early care of the injured spinal cord patient ceased. Although the rehabilitation results were spectacular compared to what had preceeded, the return of spinal cord function has remained almost unchanged from the time of Riddoch to the present. No scientifically valid effort to study clinically the hypothesis arising from experimental studies, was made until a few years ago. A patient with a spinal cord injury, although now often capable of self care and productive work, has no more significant possibility of return of spinal cord function with treatment in I 982 than he did in 1917 nor have his physicians attained any scientifically valid new information to use to increase those chances. But to return to the other series to illustrate two points. They are what happened among these series to patients with complete lesions on admission and what percent of patients deteriorated with treatment. At first glance the fact that 8 per cent of the Stoke Mandeville total functional loss or ' $A$ ' admission patients improved to a functional level would document the superiority of their 
treatment. However, the California series also had an 8 per cent improvement even though 29 per cent received early operations and almost all had rapid reduction of their fracture. Maynard in the California group reviewed the five charts that constitute that 8 per cent and found all had some impairment of consciousness at the time of the first examination. Other reasons for improvement in total lesions in other series are very early admission with improvement in the first few hours after injury, or inadequate admission neurological evaluations for any reason. In my opinion with any of the presently used treatment regimes, a series of spinal cord injury patients that has more than an occasional complete lesion patient showing functional return, indicates the authors of that series have either discovered the Holy Grail of spinal cord injury, have a large number of admissions within minutes of injury, or have an error in admission examinations. I intellectually cannot believe that slow reduction, and non concern for compression of the spinal cord for days is that sought for Grail.

Does the lack of deterioration in the Stoke Mandeville series demonstrate the superiority of the method? The California series also had no deterioration. The common denominator of both series is they are spinal cord injury centres not acute trauma hospitals. One bias may be that the referred patients have rehabilitation potential and the patients with other injuries, cardiovascular disease or other medical conditions are either not referred or referred when these conditions are stable. The Southwest Region series contains admission exams to acute hospitals and has the highest deterioration rate of these three series. Finally and perhaps most importantly, it should be noted that in reporting the Stoke Mandeville patients, the series is defined as follow, and I quote 'All patients who had had operations on the spine before admission-all patients who died in the first three months or who were discharged from Stoke Mandeville Hospital prematurely for any reason-are excluded from analysis'. The number and condition of these patients are not discussed further. From a statistical point of view, a major bias could exist with their exclusion.

I know I have been critical of the Stoke Mandeville series, not because I do not appreciate what has been accomplished there, but with critical review even their series does not disprove the hypothesis that is based on evaluation of many series and my personal experience. The hypothesis is that no treatment of spinal cord injury that is within the bounds of good medical care can be shown to be superior to any other. I conclude that none of these present series or any other series demonstrate a statistically significant better or worse result from one form of therapy rather than from another.

It is suggested from the experimental studies of spinal cord injury that there is some loss of function of the spinal cord that relates to the response of the nervous system to injury that may be controlled by therapy. In the clinical situation this may apply to only a portion of the cases and have limited effect but even that limited effect can have significance to the social problem and may mean the difference of nervous system functional life rather than a mechanical functional life for the individuals helped. Patients with rapid onset of complete loss of spinal cord function following injury are not likely to be the group where the effectiveness of any treatment can be demonstrated and I conclude, that since there is no evidence to support that any specific treatment of spinal cord injury is better we morally can 
and medically should develop prospective randomised studies in order to study and improve the acute treatment of spinal cord injury. These almost certainly will have to be multicentre studies since experimental data indicates that at the most the first 48 hours is the window for treatment and probably only the first 4-12 hours, the promising portion of the trauma-dose curve is the one containing partial lesions and there are multiple variables requiring large numbers of cases for statistical significance to be obtained. There is a paucity of cases in any one centre or even one area of the country that can fulfill the requirements for a satisfactorily rated study.

We have made a start with a randomised collaborative study but it is only just a start. In I 977 we submitted to the NINCDS following a two-year feasibility study, a project to evaluate low-dose, high-dose steroids in the treatment of spinal cord injury to be organised at Yale. The steriod used was methylprednisolone with high-dose protocol of a $1000 \mathrm{mgm}$ loading dose and $1000 \mathrm{mgm}$ per day for IO days and the low dose of $100 \mathrm{mgm}$ loading and $100 \mathrm{mgm}$ per day. I personally would have preferred a study that included a placebo arm but even though there is no clinical evidence that steroids are of value in spinal cord injury we could not get agreement of the various centres proposed for the study to use a placebo. The reasons were both moral in that they believe the experiental studies showed that it had value, and medicolegal, feeling that any physician not using steroids might be open to a malpractice suit. The first patient to enter the study was on 17 February 1979 and the last on 6 November I98I. Three hundred and thirty patients that were randomised into the two steroid treatments. The types and frequency of injuries are shown in Table V. Of the randomised patients, 24 were excluded for various reasons. The ex-

TABLE V

Distribution (in per cent) of types of injury in the National Spinal Cord Injury Collaborative Study

\begin{tabular}{lccc}
\hline & \multicolumn{2}{c}{ Treatment group } & \\
\cline { 2 - 2 } Characteristic per cent & $\begin{array}{c}\text { High } \\
(\mathrm{n}=\mathrm{I} 52)\end{array}$ & $\begin{array}{c}\text { Low } \\
(\mathrm{n}=\mathrm{I} 54)\end{array}$ & $\begin{array}{c}\text { Significance } \\
\text { test }\end{array}$ \\
\hline Cause of injury & & & \\
Automobile accident & $32 \cdot 2$ & $27 \cdot 3$ & $\mathrm{p}=0.23$ \\
Fall & $2 \mathrm{I} \cdot 7$ & $2 \mathrm{I} \cdot 4$ & \\
Missile & $\mathrm{I5} \cdot 8$ & $\mathbf{2 2} \cdot \mathrm{I}$ & \\
Water related & $\mathrm{I2} \cdot 5$ & $\mathrm{I} 4.9$ & \\
Motorcycle accident & $7 \cdot 2$ & 7.8 & \\
Crush & 5.3 & 0.7 & \\
Other & 5.3 & 5.2 & \\
Unknown & 0.0 & 0.6 & \\
\hline
\end{tabular}

cluded patients were evenly distributed between the two steroid protocols and have been analysed to show that there is no bias caused by their exclusion. The UpJohn Corporation provided the two doses of methylprednisolone in uniquely numbered look alike packages and organised random codes. They otherwise did not participate in any aspect of the trial. An advisory committee was established by the NINCDS to monitor the 
conduct of the trial and data collection and an analysis was conducted to monitor intermediate results with only two investigators, myself and an epidemiologist, Dr Bracken, being aware of the assignment of patients in the randomisation during the study. Standard forms for reporting the history, neurological examination, treatment and complications were developed during the previous two-year feasibility study. The only significant difference between the two treatments modes was a higher rate of wound infection in the high steroid group. The results of the study will be published this coming year. Only 6 weeks and 6 months follow-up are available at this time since the complete evaluation for the one year follow-up cannot be done until mid-1983. Five groups of patients were looked at and a multivariate analysis was done of the results, Quadriplegia with total sensory loss or Frankel Grade A and paraplegia with total sensory loss also a Frankel Grade A were combined as were quadriplegic with partial sensory loss and paraplegic with partial sensory loss or a Frankel Grade B, while those with some motor function and variable sensory loss or Frankel Grades C and D were combined as a group (Table VI). At 6 weeks there was a trend that suggested that the high-dose steroids may be having some effect in the $C$ and $\mathrm{D}$ group but it was not statistically significant and at 6 months there does not appear to be a statistical difference between the patients in highdose vs the patients in low-dose groups.

\section{TABLE VI}

Distribution (in per cent) of functional deficits on admission to the National Spinal Cord Injury Collaborative Study

\begin{tabular}{|c|c|c|c|}
\hline \multirow[b]{2}{*}{ Neurological status } & \multirow[b]{2}{*}{$\begin{array}{l}\text { Frankel } \\
\text { grade }\end{array}$} & \multicolumn{2}{|c|}{ Steroid protocol } \\
\hline & & $\begin{array}{c}\text { High } \\
(\mathrm{n}=\mathrm{I} 52)(\mathrm{n}\end{array}$ & $\begin{array}{c}\text { Low } \\
\mathrm{n}=\mathrm{I} 54)\end{array}$ \\
\hline Quadriplegic; Total sensory loss & A & $27 \cdot 0$ & $33 \cdot I$ \\
\hline Paraplegic; Total sensory loss & A & $24 \cdot 3$ & $27 \cdot 9$ \\
\hline Quadriplegic; Partial sensory loss & B & $4 \cdot 0$ & $5 \cdot 8$ \\
\hline Paraplegic; Partial sensory loss & B & I I 8 & $9 \cdot I$ \\
\hline Paretics; Variable sensory loss & $\mathrm{C}+\mathrm{D}$ & $32 \cdot 9$ & $24 \cdot 0$ \\
\hline
\end{tabular}

I know of the cost and the amount of work that was done attempting to evaluate a single drug two dose treatment and it produced a negative result. We as physicians must realise that any treatment which has been considered to alter the acute care of the spinal cord injured patient must be evaluated in a similar fashion. Anything less than this is not acceptable but no evaluation is even less acceptable.

In the few remaining minutes I would like to discuss the directions we are taking at Yale in our continuing work with spinal cord injury. One is a continuation of animal models in spinal cord injury in the hopes of defining mechanisms of secondary injury more accurately. Another is the continuation of the clinical series of prospective treatment protocols, and the third is the study of central nervous system regeneration. We have decided to study regeneration in the central nervous system because we 
believe it is the only hope for the majority of spinal cord injury victims. Some 20 odd years ago, I worked on central nervous system regeneration and after a few years came to the conclusion that none of the models we were using nor the methods available were able to answer even the simple question as to the ability of central nervous system neurons to regenerate. I swore, at that time, I would not get involved with central nervous system regeneration experimentation again, but now the question of central nervous system neuronal regeneration can be answered in the affirmative but whether central nervous system neurons can functionally regenerate, and what starts, stops and controls the process cannot be answered. Working with Professor Cohen in the Department of Biology, Professor Shepard in Anatomy and Dr Van den Pol in my department, we have two models of spinal cord regeneration and a model of neuronal regeneration that can be asked these questions. The first is in the Lamprey eel that does functionally regenerate a transected spinal cord and whose giant reticulo-spinal neurons make it possible to follow the course of individual identifiable fibers during regeneration (Wood and Cohen, 1979). Preliminary observations suggest anatomical junctions, including gap junctions, their numbers and positions on the regenerating axon and not glial or fibrous scar limit the amount of spinal cord regeneration in the Lamprey. They also suggest that electrical fields may alter both initial fibre die back and nondirectional branching. The second model is in the rat and is a study of a hypothalmic spinal tract that contains neurophysin. Its fibres can be identified by immunohistochemical techniques proximally and distally to a spinal cord lesion. This allows identification of regenerating fibers coming from the proximal end of a tract in a lesioned spinal cord. This model will allow studies in a mammal to check the findings of the Lamprey model. The third model of regeneration can be asked more basic questions of neuronal reorganisation during regeneration by studying olfactory neurons in the mouse and salamander (Greer and Shepherd, I982). These have been demonstrated to regenerate. All three models are under active investigation. While the work is a long way from any application to the clinical theatre, the models allow questions to be asked and data that can be evaluated to be obtained.

In summary, although considerable advances have been made in the care of the total patient with spinal cord injury, little has been accomplished in improving the spinal cord functional result. No clinical therapy for spinal cord injury has shown superiority in accomplishing the goal of protecting the spinal cord from further loss of function after injury or reversing the initial injury and no clinical studies have given support for the hypothesis that secondary injury is important in determining resulting neurological deficits. The need to clarify the problems of secondary injury is apparent but prevention of injury and techniques to re-establish spinal cord function after an injury are the most likely way of altering the problems faced by victims of spinal cord injury. Neurosurgeons probably have to be optimistic in order to continue in neurosurgery but even so the present models for regeneration are so interesting that I hope my career can extend as long as it will be necessary to study these and other models that are certain to be developed. I am too old to believe that we can prevent our population from killing or maiming themselves and, therefore, I hope that sometime in the future a Dott lecturer can announce that techniques for 
functional regeneration of the central nervous system are available or at least close to hand, I certainly cannot, but I believe a future lecturer will.

\section{REFERENCES}

Albin, M. S., White, R. J., Acosta-RuA, G. et al. (1968). Study of functional recovery produced by delayed cooling after spinal cord injury on primates. $\mathcal{F}$. Neurosurg., 29, I I 3-I 20.

Allen, A. R. (I9I I). Surgery of experimental lesion of spinal cord equivalent to crush injury of fracture dislocation of spinal column. F.A.M.A., 57, 878-890.

Allen, A. R. (I9I4). Remarks on the histopathological changes in the spinal cord due to impact. An experimental study. F. Nerv. Ment. Dis., 4I, I4 I-I 47.

BenEs, V. (I968). Spinal cord injury. Bailliere, London.

BlaCk, P., MARKowITZ, R. S. (I97I). Experimental spinal cord injury in monkeys: comparison of steroids and local hypothermia. Surg. Forum, 22, 408-4I I.

Botteral, E. H., Jousse, A. T., Kraus, A. S. et al. (1975). A model for the future care of acute spinal cord injuries. Can. F. Neuro. Sci., 2, 36I-380.

Bracken, M., Freeman, D. H. \& Hellenbrand, K. (I98I). Incidence of acute traumatic hospitalized spinal cord injury in the United States, 1970-1977. Am. F. Epidemiology, I13, 615-622.

Braughler, J. M. \& Hall, E. D. (1982). Correlation of methyl prednisolone levels in cat spinal cord with its effects on $\left(\mathrm{Na}^{+}+\mathrm{K}^{+}\right)$- ATPhase lipid peroxidation and alpha motor neurone function. F. Neurosurg., 56, 838-844.

Brodner, R. A., VANGilder, J. C. \& Collins, W. F. (I98I). Experimental spinal cord trauma: Potentiation by alcohol. F. Trauma, 124-129.

Campbell, J. B., DeCrescito, V. \& Tomasula, J. (I973). Experimental treatment of acute spinal cord contusion in the cat. Surg. Neurol., I, 102.

Campbell, J. B., DeCrescito, V., Tomasula, J. J. et al. (I974). Effects of antifibrinolytic and steroid therapy on the contused spinal cords of cat. F. Neurosurg., 40, 726-733.

Collins, W. F. \& KAUER, J. S. (I979). The past and future of animal models used for spinal cord trauma. In Neural Trauma, Popp, A. J. et al. (eds), Raven Press, New York.

DeEcke, L. \& TAtor, C. H. (1973). Neurophysiological assessment of afferent and efferent conduction in the injured spinal cord. F. Neurosurg., 39, 65-74.

DE LA TORRE, J. C. (I98I). Spinal Cord Injury: review of basic and applied research. Spine, 6, 31 5-335.

DE LA TORRE, J. C. \& Boggan, J. E. (I980). Neurophysiological monitoring in rat spinal cord trauma. Exp. Neurol., 70, 356.

Dolan, E. J., Tator, C. H. \& Endrenyi, R. (I980). The value of decompression for acute experimental spinal cord compression injury. F. Neurosurg., 53, 749-755.

Dohrmann, G. J. (1972). Experimental spinal cord trauma. A historical review. Arch. Neurol., 27, 468-473.

Dohrmann, G., Panjabi, M. \& Banks, D. (1978). Biomechanics of experimental spinal cord trauma. F. Neurosurg., 48, 993-100I.

Ducker, T. B. \& HAMIT, H. I. (I969). Experimental treatments of acute spinal cord injury. F. Neurosurg., 30, 693-697.

Ducker, T. B., Kindt, G. W. \& Lempe, R. G. (I97I). Pathological findings in acute experimental spinal cord injury. F. Neurosurg., 35, 700.

Eidelberg, E., Straehley, D., ERspamer, R. \& Watkins, C. F. (1977). Relationship between residual hindlimb-assisted locomotion and surviving axons after incomplete spinal cord injuries. Exp. Neurol., 56, 312-322.

Faden, A. I., Jacobs, T. P. \& Holaday, J. W. (I98Ia). Opiate antagonists improve neurologic recovery after spinal cord injury. Science, $211,493-494$.

FAden, A. I., JacoBs, T. P., Mongey, E. et al. (I98Ib). Endorphins in experimental spinal injury: therapeutic effect of naloxone. Ann. Neurol., 10, 326-332.

FerRARO, A. (1927). Experimental medullary concussion of the spinal cord in rabbits: histological studies of the early stages. Arch. Neurol. Psychiat., 18, 357-373.

Flamm, E. S., Demopoulos, H. B., Seligman, M. L. et al. (1977). Ethanol potentiation of central nervous system trauma. F. Neurosurg., 46, 328-335.

Flamm, E. S., Young, W., Demopoulos, H. B. et al. (1982). Experimental spinal cord injury: treatment with naloxone. Neurosurg., 10, 227-23I. 
Frankel, H. L., HanCock, D. O., Hyslop, G. et al. (1967). The value of postural reduction in the initial management of closed injuries of the spine with paraplegia and tetraplegia. Paraplegia, 7, I79-192.

FreEmAN, L. W. \& WRIGHT, T. W. (1953). Experimental observations of concussion and contusion of the spinal cord. Am. Surg., 137, 433-443.

GeHRIG, R. \& Michaelis, L. S. (I968). Statistics of acute paraplegia and tetraplegia on a national scale. Switzerland, I960-67. Paraplegia, 6, 93-95.

Greer, C. A., Shepherd, G. M. (1982). Mitral cell degeneration in the neurological mutant mouse PCD. Brain Res., 235, I56-I6I.

GRIFFITHS, I. R. (1976). Spinal cord blood flow after acute experimental cord injury in dog. F. Neurol. Sci., $27,247$.

Hall, E. D., BRaughler, J. M. (I98I). Acute effects of intravenous gluocorticoid pretreatment on the in vitro peroxidation of cat spinal cord tissue. Exp. Neurol., 73, $32 \mathrm{I}-324$.

Hall, E. D., Braughler, J. M. (1982). Glucocorticoid mechanisms in acute spinal cord injury: A review and therapeutic rationale. Surg. Neurol., 15, 320-322.

HARTWELL, J. B. (I9I7). An analysis of I 33 fractures of the spine treated at the Massachusetts General Hospital. Boston Med. Surg. F., 177, 31-4I.

Hedeman, L. S., SHELlENBERGER, M. K. \& GoRdON, J. H. (1974a). Studies in experimental spinal cord trauma. Part I: Alterations in catecholamine levels. F. Neurosurg., 40, 37-43.

Hedeman, L. S. \& Sil, R. (I974b). Studies in experimental spinal cord trauma. Part 2: Comparison of treatment with steroids low molecular weight dextran and catecholamine blockade. F. Neurosurg., 40, 46-5I.

Joynes, J. \& FreEman, L. W. (1963). Urea and spinal cord trauma. Neurol., 13, 69-72.

Kraus, J. F., Franti, C. E., RIGGINS, R. S. et al. (1975). Incidence of traumatic spinal cord lesions. F. Chronic Dis., 28, 47I-492.

Kraus, J. F. (1980). Injury to the head and spinal cord. Suppl. F. Neurosurg. The National Head and Spinal Cord Injury Survey. 53, $\mathrm{S}_{3}-\mathrm{S}_{\mathrm{I}} \mathrm{O}$.

Lewin, M. G., Hausebrut, R. R. \& Pappius, H. M. (I974). Clinical characteristics of traumatic spinal cord edema in cats. Effects of steroids on potassium depletion. $\mathcal{F}$. Neurosurg., 40, 65-75.

MCVEIGH, J. F. (1923). Experimental cord crushes with special reference to the mechanical factors involved and subsequent changes in the area of the cord affected. Arch. Surg., 7, 573-600.

Maynard, F. M., Reynolds, G. G., Fountain, S. et al. (1979). Neurological prognosis after traumatic quadriplegia. $\mathcal{F}$. Neurosurg., 50, 6I I-6I6.

Means, E. D., ANDerson, D. K., Water, T. R. et al. (1981). Effect of methylprednisolone in compression trauma to feline spinal cord. $\mathcal{F}$. Neurosurg., 55, 200-208.

Mixter, S. J. \& Chase, H. M. (1904). Operation in spinal cord injuries. Annal. Surg., 39, 495-5 I I.

Naftchi, N. F., Demeny, M., DeCrescito, V. et al. (I974). Biogenic amine concentration in traumatize spinal cords of cat. Effect of drug therapy. $\mathcal{F}$. Neurosurg., 40, 52-57.

NemeCEK, S. (1978). Morphological evidence for microcirculatory disturbances in experimental spinal cord trauma. In Advances in Neurology, Vol. 20, Cervos-Navarro, J. (ed.), Raven Press, New York.

Osterholm, J. L. \& MAthews, G. J. (1972a). Altered neorpinephrine metabolism following experimental spinal cord injury. Part $\mathrm{I}$ : Relationships to hemorrhagic necrosis and post wound neurological defects. F. Neurosurg., 36, 386-394.

Osterholm, J. L. \& Mathews, G. J. (I972b). Altered norepinephrine following experimental spinal cord injury. Part 2: Protection against traumatic spinal cord hemorrhagic necrosis by norepinephrine synthesis blockade with alpha methyl tyrosine. f. Neurosurg., 36, 395-401.

Ramon, Y CajaL, S. Degeneration and regeneration of the nervous system. R. M. May (Translation) Oxford University Press, London, 1928.

Rawe, S. E., Copeland, P. M. \& Roth, R. H. (I977a). Segmental norepinephrine and dopamine levels in cat spinal cord. Life Sci., 2I, I409-14I6.

Rawe, S. E., Roth, R. H., Boadle-Biber, M. \& Collins, W. F. (1977b). Norepinephrine levels in experimental spinal cord trauma. Part $\mathrm{I}$ : Biochemical study of hemorrhagic necrosis. F. Neurosurg., 46, 342-349.

Rawe, S. E., Roth, R. H. \& Collins, W. F. (1977c). Norepinephrine levels in experimental spinal cord trauma. Part 2: Histopathological study of hemorrhagic necrosis. f. Neurosurg., 46, 350-357. 
RIDDOCH, F. (I9I7). The reflex functions of the completely divided spinal cord in man compared with those associated with less severe lesions. Brain, 40, 264-402.

Rivlin, A. S. \& TATOR, C. H. (1977). Objective clinical assessment of motor function after experimental spinal cord injury in the rat. $\mathcal{f}$. Neurosurg., 49, 577-581.

Rivin, A. S. \& TATOR, C. H. (1978). Effect of duration of acute spinal cord compression in a new acute cord injury model in the rat. Surg. Neurol., 10, 39-43.

Schamus, H. ( 1890$)$. Bertrage zur pathologischeu anatomie der Riickenmarkserschiittering. Virchous Arch., I22, 470-495.

Senter, H. J. \& Venes, J. L. (I978). Altered blood flow and secondary injury in experimental spinal cord trauma. F. Neurosurg., 49, 569-578.

SENTER, H. J., VENES, J. L., KAUER, J. S. (I979). Alteration of post-traumatic ischemia in experimental spinal cord trauma by a central nervous system depressant. $\mathcal{F}$. Neurosurg., 50, 207-216.

SPILLER, W. G. (I 899). A critical summary of recent literature on concussion of the spinal cord with some original observations. Am. F. Med. Sci., 118, 190-198.

STEWART, W. B. \& WAGNER, F. C. (I979). Vascular permeability changes in contused feline spinal cord. Brain Res., 169, I63-167.

SutToN, N. G. (1973). Injuries of the spinal cord: the management of paraplegia and tetraplegia. Butterworths, London.

TARLOv, I. M. (1957). Spinal cord compression mechanisms of paralysis and treatment. C. C. Thomas Publ.

Tarlov, I. M., Klinger, H. \& Vitales, S. (I953). Spinal cord compression studies: I. Experimental techniques to produce acute and gradual compression. Arch. Neurol. Psychiatry, 70, 813-819.

Tarlov, I. M. \& Klinger, H. (1954a). Spinal cord compression studies. II. Time limits for recovery after acute compression in dogs. Arch. Neurol. Psychiatry, 71, 271-280.

Tarlov, I. M. (1954b). Spinal cord compression studies. III. Time limits for recovery after gradual compression in dogs. Arch. Neurol. Psychiatry, 71, 588-597.

TATOR, C. H. (1972). Acute spinal cord injury: a review of recent studies of treatment and pathophysiology. Canad. Med. Ass. F., 107, 143-1 50.

TATOR, C. H. \& DEEKE, L. (I 1973). Value of normothemic perfusion, hypothermic perfusion and durotomy in the treatment of experimental acute spinal trauma. $\mathcal{F}$. Neurosurg., 39, 52-64.

WATSON, B. A. (I89I). An experimental study of lesions arising from severe concussions. Centralbl Allgem. Pathol., $2,74$.

WebB, S. B., BERZINS, E. \& WENDGARTNER et al. (1978). First year hospitalization costs for the spinal cord injured patient. Paraplegia, 15, 3 I I-3 I 8 .

Wood, M. R. \& CoHEN, M. J. (1979). Synaptic regeneration in identified neurons of the lamprey spinal cord. Science, 206, 344-347.

Young, J. S. \& DexteR, W. R. (I978). Neurological recovery distal to the zone injury in I 72 cases of closed traumatic spinal cord injury. Paraplegia, 16, 39-40.

Young, W., Flamn, B. D., Demopoulos, H., Tomasula, J. J. \& DeCrescito, V. (I98i). Effect of naloxone on post-traumatic ischemia in experimental spinal contusion. $\mathcal{F}$. Neurosurg., 55, 209-219. 